\title{
TEMPO DE RESISTÊNCIA: o discurso de protesto na poesia de Chico Buarque
}

\section{Time of resistance: the protest speech in poetry of Chico Buarque}

Luiz Benigno dos Santos Filho ${ }^{1}$

Vanessa Raquel Soares Borges ${ }^{2}$

RESUMO: A Música Popular Brasileira (MPB) teve papel significativo no envio de mensagens subliminares contra a Ditadura Militar, que vigorou no Brasil entre 1964 a 1985. Nesse sentido, o discurso musicado do compositor/cantor Chico Buarque circulariza mensagens em forma de protesto contra a ditadura, menos explícita por causa da censura, e, ao mesmo tempo, mais combativa. Deste modo, o presente artigo pretende examinar o tipo de mensagem contida nas "canções de protesto", de Chico Buarque no período do regime militar. Do arquivo coletado, selecionamos apenas três das principais músicas desse período: "Apesar de você" (1970), "Cálice" (1973) e "Acorda amor" (1974), cuja análise se pautou não só na sua estrutura, mas no seu acontecimento, enquanto discurso de protesto, ou seja, na importância de sua produção e circulação na sociedade. Dessa forma, esta pesquisa está subsidiada em autores, como: Napolitano (2002), Tatit (2004), Caldas (1985), Silva (2008), Mota (2001), Bosi (2008), Foucault (1996), Menezes (2002), entre outros caros à discussão.

Palavras-chave: Chico Buarque. Ditadura Militar. Discurso de protesto. Resistência.

ABSTRACT: Brazilian Popular Music (MPB) played a significant role in sending subliminal messages against the Military Dictatorship that was in force in Brazil between 1964 and 1985. In this sense, the music discourse of the composer / singer Chico Buarque circulated messages in the form of protest against the dictatorship, less explicit by cause of censorship, and at the same time more combative. In this way, the present article intends to examine the type of message contained in the "songs of protest", of Chico Buarque in the period of the military regime. From the collected archive, we selected only three of the main songs of that period: "Despite you" (1970), "Chalice" (1973) and "Acorda amor" (1974), whose analysis was based not only on its structure, but on its event as a protest discourse, that is, in the importance of its production and circulation in society. This research is supported by authors such as: Napolitano (2002), Tatit (2004), Caldas (1985), Silva (2008), Mota

\footnotetext{
1 Professor de Língua Portuguesa da Educação Básica (SEDUC-MA). Especialista em Letras Português e Literatura pela Faculdades Integradas de Jacarepaguá (FIJ). E-mail: luizbenignofilho@yahoo.com.br

${ }^{2}$ Mestre em Letras - Estudos da Linguagem (UFPI). Professora Assistente da Universidade Estadual do Piauí (UESPI), campus Josefina Demes. E-mail: vanlock18@hotmail.com
} 
(2001), Bosi (2008), Foucault (1996) Menezes (2002), among others expensive to the discussion.

Keywords: Chico Buarque. Military dictatorship. Protest speech. Resistance.

\section{CONSIDERAÇÕES INICIAIS}

Você corta um verso, eu escrevo outro Você me prende vivo, eu escapo morto

De repente, olha eu de novo

Perturbando a paz, exibindo o troco

(Paulo César Pinheiro \& Maurício Tapajós,

Pesadelo, 1972)

A música é arte que encanta e seduz pelos sons, mas também, pelas palavras. Em um dado contexto, ela será a tradutora dos dilemas, sonhos e esperanças das pessoas que a buscam como forma de evadir-se duma realidade eufórica e problemática. No Brasil, ela ocupa "um lugar privilegiado não apenas para ouvir música, mas também para pensar música", como diz Napolitano (2002, p.109).

O texto poético presente nas canções faz da arte um campo de interação entre Música e Literatura, expandindo-se, consideravelmente, nos últimos anos. Nesse sentido, o compositor/cantor Chico Buarque consegue notável fusão poéticomusical que impressionam leigos e especialistas.

A importância desse compositor dentro da música brasileira é inegável. Seu talento e versatilidade fazem de Chico o maior compositor do país. A linguagem sutil e irônica o define como um artesão da palavra. No entanto, toda essa aptidão musical foi coibida quando se instalou no Brasil, em 1964, o Regime Militar.

Sua obra sofreu os respingos da censura em todas as vertentes, chegando ao ponto de sofrer pré-censura somente pelo fato de ser ele o compositor. A perseguição dos censores faz com Chico se auto exilasse, na Europa. Toda essa censura e proibição são sentidas em suas canções pela forma de resistência frente a esse sistema opressor. Utiliza-se de recursos poéticos para lesar os censores e a ditadura. A metáfora foi o artifício mais usado pelo autor. Por meio dela, fazia ecoar, no dito, a indignação do presente momento, o que fez sua poesia de protesto circularizar como uma espécie de herança histórico-político-ideológica na Música Popular Brasileira (MPB). 
Assim, mesmo ameaçado pelo Regime Militar brasileiro, o compositor emana discursos de enfrentamento através da Arte: a música. Entre "cortes nas canções" e "respostas dadas", a poética musicada de Chico torna-se uma das mais relevantes da cultura brasileira.

É nesse sentido, que nos engajamos nesse trabalho, como um gesto de leitura sobre a luta por uma democracia de direitos e pelo fortalecimento da MPB como arma política de neutralização do regime político brasileiro, haja vista que o movimento foi considerado um espaço de protestos contra a Ditadura Militar e que as canções de Chico Buarque foram de suma importância para esse embate.

Para tanto, utilizamos três das suas principais músicas desse período "Apesar de você" (1970), "Cálice" (1973) e "Acorda amor" (1974), explicitando como essas canções, dado pela habilidade e requinte na linguagem, quanto pelo modo como o autor utiliza as palavras e diversas expressões, manifestavam-se como um canto de protesto e repulsa contidas em mensagens direcionadas ao regime militar.

\section{A MÚSICA EM POESIA OU POESIA MUSICADA}

Relacionar Literatura e Música é oscilar a discussão entre o suposto perigo representado pela quebra das fronteiras entre música e poesia. Surge, então, a indagação: o que define o abismo entre a Literatura e a canção, entre o poemapoema e o poema-letra-de-música?

Na cultura literária e musical, o impasse entre poesia e canção é histórico. A partir do século $\mathrm{XVI}$, com o movimento artístico Humanismo, inicia-se uma renovação na cultura portuguesa, que deixou marcas na sua produção artística: a música torna-se polifônica; na Literatura, a poesia passa a ter como centro de interesse o próprio homem e a realidade dos fatos. As duas produções se coadunam formando as cantigas trovadorescas. Com o fim dessas cantigas, a poesia palaciana surge marcando o desligamento entre poesia e música. No entanto, a partir de meados da década de 1980, com a flexibilização e a interdisciplinaridade no campo dos estudos literários, os laços entre Música e Literatura foram se estreitando, constituindo um universo bastante diversificado de estudos.

No Brasil de hoje, a poesia é mais divulgada nas letras da música popular. A própria canção popular tem-se alimentado da Literatura. Nesse aspecto, o gênero MPB mostra o quanto é limítrofe a relação entre esses dois ramos artísticos. A esse 
respeito, percebemos, nas palavras de Leminski (1986, p. 28), o grande prestígio da canção popular no Brasil, ao dizer o poeta que:

[...] na nossa geração, o centro da poesia se deslocou do livro pra música popular. Com a geração que produziu Caetano e Chico Buarque, viu se deslocar o pólo da poesia, do suporte livro pro suporte disco. De repente os dois poetas da nova geração não estão editando livros. São músicos que fazem letras e estão gravando discos. Realmente, não existe nenhum poeta escritor que você possa contrapor a Caetano e Chico na música popular. Com Caetano e Chico aconteceu uma coisa na música brasileira. Uma coisa muita grande, uma mudança de códigos. E isso prosseguiu. A associação entre poesia e música tende a se tornar cada vez maior em termos de Brasil. Os poetas mais bem dotados, mais talentosos vêm, pelo menos, prestando muita atenção na poesia dos letristas da música popular.

Na questão acima destacada, a articulação entre texto e música gera uma problemática, quando da aplicação do termo "poeta", usado de forma indistinta, tanto para cancionistas, quanto para aqueles que tradicionalmente recebem essa designação. Mas, a diferença entre os dois não se limita apenas ao "suporte" mencionado (disco e livro), mas também, aos aspectos formais e pragmáticos.

Ainda sobre essa relação literário-musical observamos um forte caráter de transformação na canção brasileira ou como diz Tatit (2004, p. 12):

É o organismo que ludibria os observadores por jamais se apresentar
com o mesmo aspecto. Por isso, a canção brasileira converteu-se em
território livre, muito frequentado por artistas que não se
consideravam nem músicos, nem poetas, nem cantores, mas um
pouco de tudo isso e alguma coisa.

É por isso que o precipício que marca a duplicidade verbal/musical fixa também, o sustentáculo, representando o enriquecimento da cultura, ao juntar a letra de música ao patrimônio da Literatura. As interinfluências entre as duas áreas, assinalada tanto pela valorização das poesias pelos cantores, quanto pela inspiração dos poetas com a música, é que torna satisfatória e produtiva a relação.

\section{MÚSICA POPULAR BRASILEIRA (MPB): DRIBLANDO A CENSURA}

Em meio à efervescência dos movimentos político-sociais e ao "caos" da Ditadura Militar, nasce um estilo de música que irá travar um bom e necessário 
combate contra esse regime, a MPB. Surgindo da Bossa Nova no ano de 1959, esse novo estilo propagou-se durante os anos de 1960 a 1980. A nova geração de músicos e compositores, que lutou contra esse sistema, valorizando a cultura da Música Popular Brasileira, buscou sua identidade através de uma canção que expressasse a ideologia nacional-popular.

A música popular sempre esteve dotada de alto grau de reconhecimento como manifestação artística na cultura brasileira, sendo a própria música, no sentido estrito, a reveladora dos anseios nacionais e veículo no ideal imaginário da população, pois conforme Napolitano (2002, p. 39) "a música, sobretudo a chamada 'música popular', ocupa no Brasil um lugar privilegiado na história sociocultural, lugar de mediações, fusões, encontros de diversas etnias, classes e regiões que formam o nosso grande mosaico nacional".

Com o autoritarismo regido pelos governos militares, cresce 0 recrudescimento das forças armadas. O então presidente, Arthur da Costa e Silva, assinando o Ato Institucional nำ, em 1968, dá seguimento a um estado de violência e tortura contra os artistas e de censura prévia aos veículos comunicativos e as canções em todo território nacional. A respeito dessa condição e das imposições políticas, Caldas (1985, p. 59-60) comenta:

O Brasil viveria seus próximos cinco anos num verdadeiro clima de terror político, revivendo os tempos do Estado Novo, do rádio e do DIP. Da mesma forma que naquela época, como já vimos, agora também nossa produção cultural era peneirada. Em fins dos anos 60 e início dos anos 70, repetindo antigos esquemas, só viriam a público a música, a peça de teatro, o livro, enfim, o produto cultural que os censores julgassem adequados ao momento político.

Assim, onde há poder, há resistência. Por trás de toda ação repressiva existe um ato contestatório. Ao passo que o poder repressivo tende a controlar o máximo as ações dos homens, diminuindo seus atos, as manifestações de resistência exercem como afrontamento, relações de força e situações estratégicas de disputa e luta.

Para os romancistas da década de 60/70, do século XX, utilizar seus textos como forma de resistência à Ditadura Militar no Brasil era um enfrentamento diante desse regime. Por isso, era indispensável o uso de técnicas que transmitissem uma mensagem politizada com toda sutileza necessária para passar pela censura. Com 
os artistas da MPB não era diferente. Estes também, compactuavam das mesmas manobras dos escritores para transmitirem suas mensagens ao público, sem serem surpreendidos pelo poder repressivo dos militares, desempenhando um papel importante na articulação das expressões para os cidadãos opositores do regime.

Nas medidas tomadas pelos compositores brasileiros como meio de contornar a censura estariam os recursos linguísticos do intertexto, como a paródia, a paráfrase, a alegoria e a metáfora. Afirmamos que a utilização do intertexto teve papel fundamental e resultado satisfatório, quando o objetivo era ser aprovado pelos órgãos censores. Em relação a esses efeitos estruturais compostos de elementos poéticos e musicais usados pelos artistas, Silva (2008, p. 150) explica que:

Para burlar a Censura, os compositores se viam obrigados a enveredar pelos caminhos do chamado desbunde (expressão utilizada para designar, na MPB, as canções cujas letras se fizeram às imagens de uma utopia não localizada no tempo ou no espaço através de "viagens", "portos", "cais", "partidas", "trens", "estações" ou "festas", "brincadeiras", "carnavais", etc.) ou na linguagem da "fresta" (expressão cunhada para as letras cujo sentido não estava no dito, mas no interdito, nas entrelinhas).

Captando o espírito da época, Vasconcellos (1977) apud Silva (2008, p. 151), fala ainda sobre essas estratégias composicionais: Segundo o autor:

[...] diante dos estorvos objetivos impingidos pela ideologia hegemônica, a metáfora - para os mais lúcidos - deixa de ser meramente uma arma de estilo para se transformar num recurso estratégico contra a afasia. A criação popular passa a se valer da elipse; do discurso reticente, do falar pela negação: abrir o jogo é uma tática suicida. $\mathrm{O}$ constrangimento do silencio ronda por perto.

Diante de tais dificuldades impostas pelo regime, o discurso musical passa a requerer um público mais especializado e atento, conferindo-Ihes até um certo status de superioridade intelectual, pois, muitas vezes, a driblagem era executada de forma tão rebuscada, que nem o público e nem os críticos tinham condições de captar os sentidos que o compositor quisera imprimir.

Portanto, concordamos com Napolitano (2002) ao dizer que as imagens de "modernidade", "liberdade", "justiça social" e as ideologias socialmente emancipatórias como um todo, impregnaram as canções da MPB, sobretudo na fase mais autoritária do Regime Militar. Pois, se a MPB sofria com esse cerceamento, a 
opressão que se abateu sobre seus artistas ajudou a materializar a atmosfera de resistência cultural e política.

Com a posterior redemocratização e abertura política do regime militar, percebemos que a MPB revelou-se uma essencial e eficaz "arma política" de combate a esse regime, consolidando com suas canções a mobilização das grandes massas, criando um clima favorável para o fim da ditadura.

\section{MEU REFRÃO: COMBATE AO REGIME MILITAR NAS CANÇÕES DE CHICO BUARQUE}

A obra musical de Chico Buarque faz uma travessia por um amplo tratamento temático relacionado aos acontecimentos (amorosos, políticos e cômicos) que cercavam a vida do autor. A proposta das "canções de protesto" analisadas será a de uma mudança da realidade do conturbado momento político, só que por meio de um caráter irreversível e não de uma momentânea trégua da realidade, utilizando nessas canções, uma "semântica de repressão" e de uma "sintaxe de repressão". Examinamos também como, introduzida na realidade da população, a repressão se torna elemento estrutural das canções.

A ordem de apresentação dessas canções ${ }^{3}$ será feita a partir da data de publicação das mesmas, com a intenção de dar uma sequência cronológica das ideias expressas, assim, temos: Apesar de você (1970), Cálice (1974), e Acorda amor (1974). É importante observar que, as canções analisadas possuem um "poder textual" muito forte frente às condições de uma realidade social conturbada. E que, por isso, destaca-se a música, que, para além do texto escrito, é acompanhada por um arranjo discursivo histórico-ideológico que reforça sua mensagem, incrustada de signos dessa realidade.

A literatura poético-musicada de Chico tem resquícios da década de 60, época marcada por intensos fervores ideológicos e sociais no Brasil. Após o Golpe de 64, à medida que essas práticas políticas se intensificavam, os instrumentos repressivos da censura se fortificavam, bloqueando todo tipo de oposição. Artistas como Chico Buarque, que tentava de todas as maneiras usar suas músicas como veículo manifesto das reivindicações sociais, tinham seus versos mutilados e eram

\footnotetext{
${ }^{3}$ As canções analisadas foram retiradas do "Songbook: Chico Buarque", de Almir Chediak (1999).
}

Cadernos Cajuína, V. 4, N. 1, 2019, p.247 - 264.

ISSN: 2448-0916 
obrigados a depor nos órgãos censores sobre o conteúdo de suas canções. A revista BRAVO! resgata o desabafo do compositor à imprensa no início da década de 70: "de cada três músicas que faço, duas são censuradas. De tanto ser censurado, está ocorrendo comigo um processo inquietante. Eu estou começando a me autocensurar. E isso é péssimo". (BRAVO!, 2009, p. 74)

A partir desse depoimento, observa-se que Chico não estava livre dos objetivos da Ditadura Militar - o de silenciar, impedindo a voz que ecoava do manifesto dos artistas, através de sua criatividade. Foi após esse estado de inconformismo social e indignação, que Chico resolveu se autoexilar em Roma, na Itália, ficando por lá mais de um ano e só retornando em março de 1970. Num quadro de necessidades financeiras, exílio, responsabilidade familiar e do "popstar apagado" ou como ele mesmo diz: "o tempo na Itália é um tempo perdido musicalmente". Chico resolve retornar ao Brasil e fica atônito ao chegar a sua pátria, como podemos verificar na seguinte declaração:

Eu vim realmente entender o que estava acontecendo quando cheguei de volta, em 1970. Era uma barra muito pesada, vésperas de copa do mundo. Foi um susto chegar aqui e encontrar uma realidade que eu não imaginava. Em um ano e meio de distância dava pra notar. Aqueles carros entulhados com os "Brasil, ame-o ou deixe-o", ou ainda o "Ame-o ou morra" nos vidros de trás. Mas não tinha outra. Eu sabia que era o novo quadro, independentemente de choques ou não. "Muito bem, é aqui que eu vou viver". Que realmente eu já estava aqui de volta. Então fiz o Apesar de você. ${ }^{4}$

Apesar de todas as censuras impostas, o início da década de 70 traz um compositor experiente musicalmente e com um senso crítico ainda maior, revelando uma preocupação com os excluídos do sistema que participavam do desenvolvimento econômico do país. Mas, essa apreensão com o semelhante é motivada por uma razão mais humana do que política. Daí a reação representada por músicas combativas e repletas de metáforas, como a emblemática Apesar de você (1970).

A relação entre Chico Buarque e a censura começou no início de sua carreira. A música Tamandaré (1965) foi proibida como justificativa de desrespeito ao patrono da marinha. Fato curioso aconteceu com Apesar de você. Esta, inclusa num compacto simples, foi enviada para aprovação da censura. Inesperadamente,

${ }^{4}$ BUARQUE, Chico. O Globo, 1979. Disponível em: < www.chicobuarque.com.br $>$. 
foi aprovada, tornando-se um sucesso imediato, vendendo mais de 100 mil cópias. Nelson Mota (2001, p. 223) finaliza este episódio dizendo:

Em poucos dias, o Brasil inteiro estava cantando "Apesar de você", como um hino de resistência, como um desafio e uma esperança. [...] Mas a alegria durou pouco: os militares não eram burros como o censor e logo perceberam o tamanho da encrenca e tomaram providências: a música foi sumariamente interditada e os discos confiscados. [...] "Apesar de você", era a proibição mais pública do Brasil, o que a fazia ainda mais popular.

Nesse contexto, estavam os desmandos e bloqueios do governo do então presidente-general, Emílio Garrastazu Médici (1969-1974), que logo o referiam ao "você" da canção. Mas, passamos a concordar que o "você" dito por Chico é muito mais que uma referência, ao mencionado ditador, mas sim, a um "estado de coisas" que se abatia por todo país. O próprio compositor esclarece este fato no DVD Vai Passar: "Apesar de você" queriam que eu dissesse que "você" fosse o Médici, mas não era. Não era um general era uma generalidade. Era uma situação. "Apesar de você" era tudo. [...] A vontade que as pessoas têm de que as coisas sejam mais diretas. Não era”. (OLIVEIRA, 2006, 41 min)

Portanto, mesmo não sendo dirigida a um 'destinatário específico', a canção se direciona a todas as formas de opressão, desde a tortura física até alguns artifícios de se inibir a inventividade do artista. Em Apesar de você, o autor começa seu diagnóstico sobre como é o dia de hoje (lembrando que se trata do período presente do autor e da canção) e que nessa nova conjuntura (política) só existe um 'governante' - e este incontestável - o poder (conduzida pelo advérbio hoje): “Hoje você é quem manda/ Falou tá falado/ não tem discussão, não [...]".

Os versos posteriores continuam retratando essa realidade repressiva do poder. E aqui, o comparamos à tese de Foucault (1996), sobre o poder disciplinar, ao questionar que este, mesmo visando à humanização, provoca violência, através de seus mecanismos de coerção e que, por isso, deixa a população com um sentimento de medo diante desse obscurantismo social ("A minha gente hoje anda/ Falando de lado e olhando pro chão"). O termo "Estado", escrito em inicial maiúscula, mesmo querendo imprimir uma dupla leitura, referindo-se às circunstâncias opressivas daquela realidade, trata-se, na verdade, da concepção 
negativa acerca do poder pelo aparelho de Estado "inventado" com o Golpe de 64 pelos militares.

\author{
A minha gente hoje anda \\ Falando de lado e olhando pro chão Viu? \\ Você que inventou esse Estado \\ Inventou de inventar \\ Toda escuridão
}

"A MPB é, antes de mais nada, uma música que carrega a possibilidade de mudanças e de sonho, na qual as metáforas indicam onde chegar" (VILARINHO, 1999, p. 68). Essas metáforas representam o dia que virá e Chico utilizou essa figura em quase todas suas "músicas de protesto". Na canção Apesar de você, esse recurso está presente na maioria das estrofes iniciadas pelo refrão: "Apesar de você/ Amanhã há de ser outro dia [...]"

Ao cantar o dia que virá, o compositor dá uma perspectiva de alteração na realidade, jogando para o amanhã essa possibilidade de "um mundo melhor". Se antes o que era dito pelos militares torna-se incontestável: "Falou tá falado/ não tem discussão [...]", no amanhã, esse valor se inverte, "buscando o abstrato dia em que a utopia cantada nas metáforas ocupasse lugar no real (VILARINHO, 1999, p. 68) (Grifo nosso)", como na prefiguração de "[...] Água nova brotando/ e agente se amando sem parar" ou no trecho irônico "Quando chegar o momento/ esse meu sofrimento/ vou cobrar com juros. Juro?'.

A estrutura do poema é recheada de um jogo de antíteses intercalado pelo refrão, como exposto no quadro abaixo:

Quadro 01: Jogos de antíteses na letra da música Apesar de você, de Chico Buarque

\begin{tabular}{|c|c|}
\hline Hoje & Amanhã \\
\hline gente falando de lado & coro a cantar céu clarear \\
escuridão pecado amor & $\begin{array}{c}\text { perdão a gente se amando } \\
\text { reprimido grito contido }\end{array}$ \\
\end{tabular}

Fonte: Elaborado pelos autores (2018)

Já na estrutura musical, o ritmo rápido do samba e as vozes ao fundo no refrão dão uma ideia de multidão a protestar em passeatas contra o poder instalado em um "coro a cantar" com "enorme euforia". Portanto, o autor projeta para a "sua 
gente" o seu "grito contido", para que o povo mobilizado para a "luta" exija justiça pela ausência de liberdade.

Suscitando a consciência da repressão, extraímos a função social de Apesar de você, que assim como os romances de resistência, estava preocupada com a problemática socioeconômica do povo brasileiro e de sua privação expressiva e que nas ações dessas artes revolucionárias "resistir é opor a força própria (arte) à força alheia (repressão)", como bem disse Bosi (2008).

No entanto, não podemos somente pensar que Chico Buarque fazia uso de suas canções para driblar a censura - que, por exemplo, ele falaria de "amor reprimido" querendo apenas se referir a uma prática política reprimida. As suas metáforas também dizem respeito a uma literalidade afetiva, e não apenas a um registro político.

O ano de 1973 foi considerado o Ano Negro da Censura às músicas da MPB. Diversos foram os discos proibidos de serem lançados, as músicas de serem tocadas, os versos cortados e alterados, as vozes silenciadas. Nesse período amargo da história brasileira, o jornalista Nelson Mota (2001, p. 263-264) recorda os momentos que também vivenciou:

Tanto o público quanto a imprensa ansiavam por novidades, surpresas, intervenções políticas, rebeldia e resistência. [...] Chico Buarque e Gilberto Gil fizeram uma música perfeita para expressar o momento e o estado de espírito que vivíamos, de repressão e sofrimento, de medo e desconfiança, apropriadamente chamada, em tempos de boca calada obrigatória, "Cálice". A música era um protesto tão sentido, tão doloroso e apropriado, tão óbvio, que a Censura Federal naturalmente a proibiu. (Grifo nosso)

Sem sombra do esperado Carnaval na música popular brasileira, Chico continuava como o artista participante em um duplo engajamento - com a palavra e a sociedade - e denunciando a ditadura, agora, formando dupla com Gil. Este "mostrou a Chico a primeira estrofe e o refrão de Cálice 'Pai, afasta de mim esse cálice', referência à data em que os escrevera, uma Sexta-feira Santa. O parceiro viu, mais do que depressa, o jogo de palavras 'cálice x cale-se' (HOMEM, 2009 p. 120) (Grifos nosso). Foi necessário mais um encontro para que concluíssem a música. 
Em Cálice, é evidente a analogia feita entre a passagem bíblica da Paixão de Cristo, no martírio de Jesus no calvário, e o sofrimento da população aterrorizada pelo regime autoritário.

Pai, afasta de mim esse cálice $(3 x)$

De vinho tinto de sangue

A alusão, no refrão, à figura de Cristo e ao drama da tortura no Brasil no período da Ditadura Militar, conduz o leitor a fazer uma breve avaliação: o cálice, objeto que contém no seu interior o vinho, representado como o sangue de Cristo e na música remete ao sangue derramado pelas vítimas da tortura e opressão. Outros versos também fazem menção ao conteúdo bíblico, como: "Como é difícil, pai, abrir a porta", expressando a busca por melhores dias, mesmo com todas as dificuldades e riscos, significando biblicamente, a procura de um novo tempo; "De que adianta ter boa vontade" no desejo de luta pela liberdade faz referência à passagem bíblica "Paz na terra aos homens de boa vontade" (Lucas 2,10-14).

No contexto questionado, a repressão invade o ritmo e o assunto nas "canções de protesto". A "semântica da repressão" é constante nos versos bem trabalhados de Cálice: boca calada, realidade morta, força bruta, palavra presa na garganta, peito calado. Esse silêncio imposto pela Ditadura é frisado, insistentemente, no refrão, em um jogo de palavras e ambiguidade entre o termo "cálice" e o imperativo "cale-se":

\section{Pai, afasta de mim esse Cálice}

(ouça-se Cale-se)

Em uma análise minuciosa, percebemos que toda a canção é recheada de silêncios que enunciam nas entrelinhas da poética metaforizada, em um dos confrontos de Chico Buarque com a repressão da Censura do governo Médici. Vejamos então, alguns dos principais versos referentes à crítica contra a ditadura:

Como beber dessa bebida amarga

Tragar a dor engolir a labuta

[...]

Silêncio na cidade não se escuta

[...]

Outra realidade menos morta

Tanta mentira, tanta força bruta 
Os versos acima destacam a violência e a censura de regime. As pessoas eram tratadas de formas desumanas, tendo que aceitar um quadro social degradante como algo natural - "tragar a dor" - em que muitos casos as condições trabalhistas eram de péssima qualidade - "engolir a labuta". Isso tudo, pela falsa realidade do "milagre econômico", propagandeado pelo regime militar.

\author{
Mesmo calada a boca, resta o peito \\ [...] \\ Como é difícil acordar calado \\ Se na calada da noite eu me dano \\ Quero lançar um grito desumano \\ Que é uma maneira de ser escutado \\ Esse silêncio todo me atordoa \\ Atordoado eu permaneço atento \\ [...] \\ Essa palavra presa na garganta \\ Esse pileque homérico no mundo
}

O "silêncio" está imbuído metaforicamente pela censura imprimida pelo regime que silencia a voz do poeta e de todos que ousassem falar e os deixam atordoado e sem sentidos pelos métodos da repressão. Mesmo tendo a liberdade de pronunciar-se coibida, resta ao poeta o desejo e a vontade dentro do seu peito de falar - "palavra presa na garganta" - aos cidadãos que estavam sob o crivo desses regimes em todo o mundo. Desafiando o cerceamento da Ditadura, o eu-lírico resolve dar seu grito, lançando sua mensagem, ainda que seja às escondidas - "na calada da noite" - ou, por conta do desespero, partindo pra o confronto - "grito desumano". Diante das torturas e imposições, o eu-lírico continua em estado de alerta - "permaneço atento" -, pois a qualquer momento, a Censura estaria silenciando-o.

Na arquibancada pra a qualquer momento Ver emergir o monstro da lagoa

Em um gesto de leitura sobre a imagem do mostro da lagoa do verso acima, utilizamos um trecho da entrevista de Chico Buarque registrado no livro de Menezes (2002, p. 93): "[...] Você pensa que a Censura é uma anomalia, uma coisa provisória. Eu acho que para o jovem compositor, a Censura é um Monstro natural, que existe, que sempre existiu, que não adianta combater. E está aí". Neste caso, Chico usa da 
alegoria para representar os mecanismos de poder imposto pela Censura (= Monstro da lagoa), através do silêncio nas canções.

De que me vale ser filho da santa

Melhor seria ser filho da outra

Os vocábulos finais dos versos labuta, escuta e bruta, da primeira estrofe causam um efeito de estranhamento, reconstruindo o palavrão sugerido em "da outra”. Não se tratando de um artifício para burlar a Censura, o xingamento é, na verdade, uma forma de atingi-la, sendo necessária uma escuta eficiente por parte do ouvinte/leitor, induzido pela semântica e sonoridade dos versos.

\section{Quero inventar o meu próprio pecado}

Quero morrer do meu próprio veneno

Utilizando a "linguagem da fresta" numa mensagem implícita nos versos, o autor deseja morrer pelos erros cometidos por ele próprio, seguindo seu livre-arbítrio e não ser punido por erros que o regime acha que ele poderá a vir cometer.

O ano seguinte ao de Cálice é marcado para Chico em uma bem sucedida tentativa de driblar a Censura com um dos mecanismos mais cômicos que aprendeu a usar e continuar produzindo em seu trabalho. Mota (2001, p. 269), revelando esse esquema, afirma que:

Depois de Calabar, tudo que fosse de Chico Buarque, qualquer coisa assinada por ele, a Censura proibia. Sem dar justificativa, em atos que não permitiam recursos ou contestação judicial. Chico se fingiu de morto, mas maquinava uma vingança terrível, que humilharia pelo humor, que driblaria o autoritarismo e a repressão com talento e malandragem. Começava a nascer Julinho de Adelaide - o novo grande nome da música brasileira, um dos poucos raios de sol nas noites silenciosas de 1974.

A incômoda sensação de mal-estar provocada pela censura à música popular revela a face mais perversa de uma das épocas mais autoritárias da história do Brasil. Essa indisposição deixou Chico numa situação insustentável, quando, de cada três músicas do compositor, uma era liberada, tendo o artista como solução a criação do compositor (personagem fictício) Julinho de Adelaide, no LP Sinal fechado (1974). As músicas Acorda, amor (1974), Jorge Maravilha (1974) e Milagre 
brasileiro (1975), de autoria do suspeito compositor, trazem o "samba duplex e pragmático", assim definido por Julinho numa arranjada entrevista concedida ao jornal Última Hora, como aquele que podia mudar de sentido quando necessário.

Nesse viés analítico-perceptivo, pode afirmar que "Acorda, amor" traz na bonita melodia e também, no texto mordaz, o protesto, dessa vez, velado, na pessoa de um suposto ladrão. "A canção descreve uma prisão muito parecida com a de Chico, quando, em dezembro de 1968, foi surpreendido dentro de casa por agentes da ditadura, que o levaram para depor" (HOMEM, 2009, p. 125).

Acorda, amor

Eu tive um pesadelo agora

Sonhei que tinha gente lá fora

Batendo no portão, que aflição

$[\ldots]$

Estes primeiros versos do samba sincopado de Julinho apresentam uma visão dramática da paranoia repressiva. O panorama social das grandes cidades brasileiras reflete no texto a inaudita violência policialesca, sugerindo a delação popular, as torturas e a insegurança, eliminando, portanto, a possibilidade de germinar uma cultura crítica. Por isso, era necessário que Chico se utilizasse desse pseudônimo para burlar a censura ${ }^{5}$.

Vivendo sob a égide dos órgãos censores e da "Doutrina da Segurança Nacional", o clima de terror e perplexidade era tão assustador que o cidadão comum preferia chamar o ladrão à polícia, como vemos nos versos abaixo:

Chame, chame, chame lá

Chame, chame o ladrão, chame o ladrão

As referências à política repressiva do regime militar são claras: a Ditadura "Era dura, numa muito escura viatura", os órgãos repressores que vinham de madrugada buscar os cidadãos subversivos em suas casas "não é mais pesadelo nada / tem gente já no vão da escada/ [...] São os homens, os desaparecimentos inexplicados dessas pessoas, Mas depois de um ano eu não vindo / Ponha a roupa de domingo e pode me esquecer", os impasses - "Se você corre o bicho pega/ Se

\footnotetext{
${ }^{5}$ Os pseudônimos duraram pouco tempo, pois a censura logo criaria a obrigação de apresentar o RG ao nome do compositor.
} 
fica não sei não" - e da incerteza sobre a companheira - "Dia desses chega sua hora/ Não discuta à toa, não reclame".

Os trechos acima põem à prova o ato contestatório não somente dos artistas inclinados nessa política de resistência, mas também, do cidadão brasileiro, que acuado nessa guerrilha urbana apela pro crime comum - "Chame o ladrão" - para escapar do crime político.

No entanto, embora seja muito "evidente" o clamor de resistência do "eu poético" no texto, a canção é passível de uma dupla leitura: o pseudo-compositor, criado por Chico, representa o sambista e o malandro do morro que tem linguajar (gírias e dialetos) típico do ambiente que ele representa, diferente do indivíduo da classe média (eventualmente, um intelectual) com linguagem elitizada. Os dois podem ser encarados pela mesma ótica como cidadãos perseguidos e presos em sua própria residência, contudo, em um plano político diferente.

Os cidadãos elitizados representariam os contestatários do regime e os malandros seriam os criminosos que são executados. Portanto, passagens da canção registradas nos versos dirão respeito, nessa segunda leitura, ao marginalizado social (malandro), mas também, por que não, aos marginalizados políticos (compositor, esquerdistas e etc.). Por exemplo, a "dura" referida anteriormente à ditadura com o malandro pode ser a "dura lei" que vitimiza essas pessoas, eliminando-as agressivamente. $O$ violão (insígnia do malandro) também é lido no duplo registro, assim como a insegurança, os desaparecimentos, os impasses e as incertezas.

Em suma, Chico, ao inventar a personagem Julinho de Adelaide, propõe-se a usá-lo como papel real do pseudônimo - velando sua identidade e a linguagem do malandro - para assim mascarar o próprio compositor (Chico Buarque), tentando evitar um novo exílio, novos depoimentos com os órgãos censores e, principalmente, as proibições nas suas músicas, privando sua criação artística. Novamente se vê o interdito na "linguagem da fresta", como alternativa estratégica contra a censura.

Ademais, vale ressaltar que em março de 1974, o general Ernesto Geisel, sucessor de Médici, assume a presidência prometendo uma distenção lenta, gradual e segura para os próximos anos na política do regime brasileiro. No entanto, a cena seria bem diferente. 


\section{CONSIDERAÇÕES FINAIS}

A música brasileira traz em sua poética um patrimônio histórico e cultural, revelando artistas. Ao circularizar discursos de protesto, tem como intuito transfigurar sua realidade para uma esfera de imaginações e utopias. O estudo da obra de Chico Buarque também aborda esse intento, imprimindo em suas canções temáticas, como - a dor, a alegria, a euforia, o caos, o protesto, o sufoco - um paradoxo que só vem a revelar os anseios e sentimentos do próprio autor.

A paixão pela palavra é utilizada como um instrumento de magia. Um dos motivos de ser tão mirado pela censura foi justamente, esse poder inquietante de lidar com as palavras. Para ele, a palavra guarda dentro de si um valor de música: vira canção. Chico declara também, que palavras e música vêm junto, uma puxa a outra.

A sua trajetória paralela à política do país, dos anos da Ditadura, fez desse artesão verbal um driblador incontestável. Os "anos de exceção" para os opositores foram tempos de rebeldia, de sentimento de solidariedade e comunhão, de sonhos de justiça e liberdade. Por isso, o sempre presente dia que virá nas suas letras buscando o "esbanjar da poesia" sem censura, sem proibições.

Porém, em meio ao discurso de opressão, só restava sonhar, pois o sentimento de liberdade e o desejo de cantar eram sempre reprimidos. As violências e torturas do pós-64 fizeram uma "desordem" social no país, deixando desigualdades, frustrações, e sede de vingança. Mas, era justamente esse ordenamento do Brasil que as gerações daquele período queriam resgatar.

Nostálgica, crítica e utópica: assim foi abordada a canção do compositor como música de resistência usando o seu universo para esmiuçar questões do país atreladas ao regime militar.

\section{REFERÊNCIAS}

BÍBLIA SAGRADA. Lucas 2,10-14. 96. ed. São Paulo: Ave-Maria, 1957. p. 57.

BOSI, Alfredo. Literatura e resistência. São Paulo: Companhia das Letras, 2008.

BUARQUE, Chico. O Globo, 1979. Disponível em: < www.chicobuarque.com.br > . Acesso em: 20 set. 2018. 
CALDAS, Waldenyr. Iniciação à Música Popular Brasileira. São Paulo: Ática, 1985.

CHEDIAK, Almir. Songbook: Chico Buarque. Rio de Janeiro: Lumiar, 1999.

Especial BRAVO! Chico. São Paulo: Editora Abril, n. 02, dezembro de 2009.

FOUCAULT, Michel. Vigiar e punir. 13. ed. Petrópolis: Vozes, 1996.

HOMEM, Wagner. Chico Buarque: histórias de canções. São Paulo: Leya, 2009.

LEMINSKI, Paulo. Anseios crípticos. Curitiba: Criar, 1986.

MENEZES, Adélia Bezerra de. Desenho Mágico: poesia e política em Chico Buarque. 3. ed. São Paulo: Ateliê Editorial, 2002.

MOTTA, Nelson. Noites Tropicais: solos, improvisos e memórias musicais. Rio de Janeiro: Objetiva, 2001.

NAPOLITANO, Marcos. História e Música: história cultural da música popular. Belo Horizonte: Autêntica, 2002.

OLIVEIRA, Roberto de. Chico Buarque: vai passar. São Paulo: EMI Music Brasil Ltda, 2006. 1 DVD-ROM.

SILVA, Alberto Moby Ribeiro Da. Sinal Fechado: a música popular brasileira sob censura (1937-45/1969-78). Rio de Janeiro: Apicuri, 2008.

TATIT, Luiz. O século da canção. Cotia: Ateliê Editorial, 2004.

VILARINHO, Ramon Casas. A MPB em movimento: música, festivais e censura. São Paulo: Olho d'Água, 1999. 